\title{
Education Leaders' Perceptions of Faculty Ethical Decision-Making: Awareness, Learning, and Change
}

\author{
Cheryl Burleigh, EdD \\ University of Phoenix, Phoenix, Arizona, United States \\ (iD) https://orcid.org/0000-0003-2393-5477
}

Contact: drcburleigh@gmail.com

\section{Abstract}

Conversations about ethical decision-making exist in a climate of misinformation within social and political forums. The issue of ethical decision-making in the context of educational leadership within a school environment has not been recently investigated. The purpose of this qualitative exploratory case study was to examine the perceptions of education leaders who observed the processes faculty employed when ethical decision-making commenced throughout the school day. Data was collected during interviews with education leaders who answered semi-structured, open-ended questions. The findings led the leaders to self-reflect, redefining their roles as authentic leaders and a gaining a deeper understanding of school culture, thus helping create systemic change.

Keywords: authentic leadership; awareness; change; education leaders; ethical decision-making

Date Submitted: March 9, 2020 | Date Published: October 28, 2020

\section{Recommended Citation}

Burleigh, C. (2020). Education leaders' perceptions of faculty ethical decision-making: Awareness, learning, and change. Journal of Educational Research and Practice, 10, 365-376. https://doi.org/10.5590/JERAP.2020.10.1.23

\section{Introduction}

Ethical decision making and employing ethics daily in a school community are practices that should be second nature. Within universities, teaching ethics to students pursuing the field of education is a required topic as either a standalone class or within the context of specific coursework to a university program (Boon, 2011; Erie, 2013). Those courses include, but are not limited to, education policy, teaching in a multicultural society, curriculum, such as integrating technology, and the ethics of research. Individuals within the education profession who pursue a higher degree or administrative credential are required to take courses in ethical leadership and decision-making, including specific case study review (Boon). The epistemology of practice promotes the rationale that, through understanding tacit and explicit knowledge, the practitioner, in this case the educator, will understand the context of how to apply professional practice when engaged in situations where ethical decision-making is needed within the classroom (Charles et al., 2016).

Education leaders assume that teachers, who earned a credential, passed subject matter mastery assessment tests, and were vetted during the district hiring process, will possess ethics and employ ethical decisionmaking. They additionally assume that educational leaders integrate ethical decision-making within a school 
and with staff based on the standards set forth by the school district (Young \& Mawhinney, 2012). Often, leaders schedule discussion of appropriate ethical decision-making practices as applied in the classroom and at a school site as a scheduled agenda topic during the pre-service week prior to the start of a school year and perhaps as a point of discussion during monthly staff meetings, professional development, or in-service work days. What guides ethical decision-making is not only based on the tenets of the school district, but also the mission and vision statements of the school (Young \& Mawhinney). Both the mission and vision statements of a school are those core values which members of the school community whole-heartedly believe best represent the principles of the school and staff and are in the interest of delivering the best possible educational experience for the students.

Ethical decision-making may be led astray, however, when teachers and staff faced a specific problem or incident which they are not sure they have the skills or competencies to resolve (Blumberg, 1989; Dolgoff et al., 2011). When presented with a situation that may involve a colleague, instead of seeking guidance from administration, a teacher or staff member may decide to tackle the problem individually, hoping for the best outcome. During this process, emotion may be involved as the faculty member reflects on the situation, how the specific situation relates to their own personal code of ethics or values, or how the outcome may affect the relationship with the colleague or other faculty and staff (van Nuland, 2009; Yamamoto et al., 2014;). Educators need courage to seek guidance when faced with an ethical situation (Jones \& Blake, 2018; McCabe, 2013). Unfortunately, educators may not have the courage or feel confident in disclosing a classroom or teacher dilemma or situation to the school's leadership, since personal loyalty to the school's faculty and staff may outweigh following through with making a decision that is ethically based (Marzano et al., 2005). Faculty may also consider the perspectives and ethics of colleagues within the school when examining their "own professional codes of ethics in light of the ethical decision-making process" (Shapiro \& Stefkovich, 2011, p. 27).

\section{Purpose}

The purpose of the qualitative exploratory case study was to address education leaders' awareness of the processes faculty at their school site employ in ethical decision making throughout the school day. The study explored education leaders' perceptions of whether an ethical climate exists within their school site, how teachers report issues that may be of ethical concern for possible investigation, and available training. By observing and reflecting on the practices of faculty at their school site, education leaders were empathetic to ethical decision-making processes. Additionally, the education leaders were able to gain a deeper understanding of how to generate innovative systemic change within their schools and empower faculty to take ownership (Hartman et al., 2017; Martin et al., 2017) to create an ethical, safe, and healthy working and learning environment (Carmel-Gilfilen \& Portillo, 2016; Kolko, 2010).

\section{Perspective and Rationale}

Campbell (2003) explored the ties of ethics to education on topics within the teaching profession, specifically learning to create an ethical culture and applied knowledge of ethics within the classroom and school community. Teachers, who are responsible for applying knowledge and creating an ethical classroom (Campbell, 2008), need to be supported by education leaders at the respective school sites. Other pertinent research focuses on a professional code of ethics existing in other countries. The Finnish teachers' ethical sensitivity study (Kuusisto et al., 2012) examined teacher's perceived ethical sensitivity within the classroom, based on training, reflection on teaching, years within the education profession, and ethical competence. In the United States, a universal professional code of ethics does not currently exist in the field of education. The teaching profession demands attention to the intangibles, those of morality and ethics, including educator conduct with students, colleagues, administration, and the school community (Campbell, 2003). 
Emerging research has demonstrated the benefits of evaluating school climate as an aspect of keeping schools safe. Research has focused on the direct relationship of student and teacher interactions via an ethical climate and principles inclusive of trust and motivation (Demir \& Karakus, 2015; Schulte et al., 2002). However, specific research on education leadership and administrators' observations and perceptions on whether an ethical climate exists within a school's culture has not been fully examined.

In a review of the future focus for leadership, Hannah et al. (2008) and Avolio et al. (2009) encouraged those in positions of leadership to examine current approaches of decision-making by staff, evolve to go beyond expectations, and welcome the challenges of meeting the demands of their school communities. Thus, empirical research and the impact of these observations and perceptions on the climate of the school site were needed to help fully understand the role and relationship of education leaders and administrators to faculty.

\section{Method and Design}

The research design, comprised of a qualitative study providing a detailed description of education leaders' perceptions of faculty ethical decision-making, was appropriate for this study (Marshall \& Rossman, 2016; Merriam, 2009; Yin, 2013). The qualitative method with an exploratory case study design was chosen to gain an in-depth understanding of the experiences of the participants. The research does not seek a quantification of data but rather an understanding of the ethical decision-making of faculty from the participant's perspective when the behavior occurs within their respective school site or district. Additionally, the research method chosen is appropriate in the context of the current literature. The qualitative method and case study design has a direct application in researching ethical decision-making of faculty, thus providing an objective way, through purposeful sampling, to capture the participants' insights during the semi-structured, openended interviews (Palinkas et al., 2015; Patton, 2002). The open-ended, semi-structured interview questions (Appendix 1) allowed the participants to honestly share, in an unrestricted environment, their observations, insights, and specific personal experiences; thus, providing for a broad, rich discussion shedding light on the topic through discovery to fill a gap in the literature on ethical decision-making by faculty, a phenomenon that has not received proper attention (Englander, 2012).

The sample population was drawn from individuals who are education leaders known to the researcher via professional associations from the San Francisco Bay Area, California. The data were from a sample of ten (10) education leaders from four different types of school systems: public, charter, and private secular and non-secular. The four men and six women who participated in the study had a minimum of five years of education leadership experience. Each of the participants was a practicing education leader, in the role of school administration at a specific school site or at the school district level. The education leaders consisted of one superintendent, six principals, and three assistant principals. The selection of participants was unbiased for gender, age, and ethnicity. Each shared personal experiences and observations of faculty ethical decisionmaking and how those observations manifested in awareness, innovative systemic change within the school site or district, and further focus on their qualities of authentic leadership.

Data were collected via interviews, document analysis, and observations with a purposeful sample of ten education leaders. Participants were asked to complete a questionnaire prior to the interview and to provide public documents and faculty memos pertaining to ethical decision-making within their school and district. Observations were limited to professional interactions between the participant and researcher. Semistructured interviews allowed the researcher to start with general open-ended questions and follow up with probes. The researcher who conducted the interviews was an instrument of the study and developed a relationship with participants. The nature of interviewer/participant relationships directly influenced the amount and depth of data. Transcriptions of the interviews were sent to each of the participants to review and confirm that their comments were accurately represented. Credibility was enhanced through the process of 
engagement with the participant during the interview and upon review of the transcripts. Data triangulation furthers validity when the depth and breadth of questions during the interview process, both semi-structured and open-ended questions, produces data that complement one another; thus, minimizing bias (Feldman et al., 2018). Data saturation is a process of triangulation when concurrent review and data analysis take place from one interview to the next. The process of data saturation, where no new ideas were evident, was reached after ten interviews (Saunders et al., 2018). A content analysis approach using inductive thematic saturation was employed since flexibility of analysis allows researchers to describe the data in a more systematic way (Finfgeld-Connett, 2013; Saunders et al., 2018; White \& Marsh, 2006). The use of qualitative analysis provided an interpretive platform to review the education leaders' perceptions where no one right or definitive answer occurs. Thus, content analysis, a descriptive process, afforded the researcher the capacity to identify descriptions from the interactions with each participant. Without this data, education leaders may not fully understand the role and relationship of faculty to the importance of making sound ethical decisions for the betterment of the school community and to further their leadership (Schulte et al., 2002).

The researcher conducted data analysis using traditional qualitative research methods including coding, categorizing, and thematic analysis (Saldana, 2015; Saunders et al., 2018). Notes were read separately and compared to find commonalities, followed by thorough analysis of the data. During the initial phase of analysis, demographics were identified and pseudonyms assigned. The inductive analysis process was employed where a comprehensive understanding of the data was expounded, including units of meaning and findings (Ziegler et al., 2006). To visually denote each of the themes and establish codes, the researcher highlighted the text in five different colors in a Word document (Johnston et al., 2017; Saldana, 2015). The coding process via connecting resultant passages from the interviews aided in the identification of reoccurring themes. This alignment of themes based on education leaders' responses substantiated the original research question:What are education leaders' perceptions of faculty ethical decision-making? The process of reflexive engagement, moving reflective learning to action (Dawson \& Kelin, 2014), provided a vehicle for the researcher to further contemplate the topic of ethical decision-making and its relationship to current research, which increased validity.

\section{Results}

The content analysis of the education leaders' perceptions of ethical decision-making at their school site or within the district revealed the following themes: Teachers differ in their understanding of ethical decisionmaking; teacher experience and training may have a direct effect on handling and reporting situations of ethical decision-making; and self-preservation demonstrated a direct correlation between ethical decision making of faculty to the education leadership at the school. Each of the education leaders found that staff awareness of what constitutes ethical decision-making is a critical issue.

\section{Teachers Differ in Their Understanding of Ethical Decision-Making}

Education leaders observed that the majority of the faculty greatly differs in their understanding of ethics, ethical behavior, and ethical decision-making. Each of the participants agreed that ethics leading to ethical decision-making are embedded in the policies of the school and district, yet teacher understanding and comprehension of how and when to enact these policies do not take place consistently. The perception of the education leaders is that faculty at their school site or within a school district have difficulty understanding when and where to apply ethical decision-making in context of a colleague, a specific classroom situation, or dealing with a parent. Sara, a superintendent and former high school administrator, noted "the bending of the rules or this does not apply to me is a common reply when a faculty member is asked why a policy as stipulated by the school and district was not enacted." When conversing with faculty, Mike, a high school assistant principal, stated, "faculty, when confronted by a situation, handle the instance in a manner they believe is best, regardless of the outcome, even if the result breaks the rules or policies of the school. Who 
would be the wiser if no one knows?" Examples shared by the education leaders included taking gifts, physical or monetary, from parents in exchange for changing a student's final grade in a class, having relationships with students, and looking the other way when a colleague was involved in selling narcotics to students. Each of the education leaders expressed concern that a standard or uniform code of ethics, for which educators are held accountable, does not exist for the teaching profession. George, a middle school assistant principal, shared, "without accountability to a standard or uniform code of ethics, faculty can play dumb, saying they didn't know. How does this help us as administrators when we need to write disciplinary action on a faculty member? They should know better." Education leaders who participated in this study acknowledged the National Education Association (NEA), the Association of American Educators (AAE), and individual states each have code of ethics, which are similar in ideology, yet not the same in defined tenets of responsibility by the practicing educator. Other professions, such as law and medicine, have a code of ethics and those practitioners within each of these professions must pass an examination prior to practicing in the field. The education leaders also reflected on their professional university teacher education programs, including undergraduate, graduate, and credentialing programs in teaching and administration. Each of the education leaders had indicated they were required to take classes in ethics and ethical decision-making, including reviewing specific case studies regarding current cases in which unethical practices had occurred. Abbie, an elementary school principal, commented:

The importance of ethical decision-making was stressed throughout both my teacher education and administrator credentialing programs. The understanding of proper conduct within the classroom, with colleagues, students, and the school community was not only stressed, but also the ramifications if unethical behavior took place.

The education leaders wondered if they should assume that all faculty were required to take classes on ethical decision-making during their respective university and credentialing programs. Based on the observations of the education leaders who took part in this study, additional and continuous training is needed on ethical decision-making of faculty and should be mandated by the school district.

\section{Teacher Experience and Training}

The education leaders felt teacher experience and training may have a direct effect on handling and reporting situations of ethical decision-making. The perception of education leaders is that faculty may passively apply professional development workshop training to ethical decision-making and rely more on their common sense or modeling of other faculty to possibly step forward when unethical behavior occurs. Professional development training may have been inadequate or did not address the types of situations the faculty actually encountered; thus, the teacher did not have the skill set and possible solutions. Education leaders noted that faculty did not feel that professional development included and considered situations that may be out of teacher control or how to handle the "fall out" of reporting a situation. Joe, a high school assistant principal, reflected, "teacher experience largely plays in how the reporting of unethical behavior happens-if the reporting happens at all. Permanent status teachers are more likely to report an instance of unethical behavior since they know they are protected by the union.” Bella, a high school principal, observed:

Faculty who are new to a school are still trying to feel where they belong in the pecking order. If they see unethical behavior, they are more likely not to report the instance no matter how egregious. The new teachers are worried about getting along with the other teachers, especially those in their department, having a reputation as a team player, and keeping their jobs.

Other education leaders noted the teacher union plays a strong role in teacher ethical decision-making and how unethical events are reported. Several participants explained faculty ethical decision-making, stating that teachers would rather report a situation that is unethical to the teacher union since anonymity is upheld, the matter is kept in the confidence of the union site steward, and the union would then take responsibility of 
reporting to the school's administration or the school district. The education leaders further stated that, while the faculty prefer anonymity for self-preservation, the delays in reporting unethical behavior do more harm than good. Several education leaders, reflecting on teacher experience and training, mentioned the "us versus them" mentality. They stated that when they moved from the ranks of a teacher to that of an administrator, congeniality and the lines of communication changed. Instead of considering the new education leaders colleagues or peers, former colleagues viewed them as bureaucrats who could not be trusted. This break down or change in school culture has led in some cases to animosity. Betty, an elementary school principal, eloquently reflected:

Becoming a principal at the school in which I had taught for 10 years was a dream come true. I never would have imagined the faculty, who I thought were family, would no longer feel confident in sharing unprofessional conduct within the school community.

Several education leaders echoed this observation. Prior to becoming school administrators, each believed they would gain an advantage in mutual respect and earned confidence by having taught at the school in which they were now an administrator. Further, the education leaders believed the advantage would translate to strengthening the school culture and promoting sound ethical decision-making of faculty. Participants reported a far different experience in which the new identity as a bureaucrat led to a lack of trust and support from former colleagues.

\section{Self-Preservation}

Education leaders described self-preservation as a teacher's understanding of self within the context of the hierarchy of the school and department in which they teach and the professional relationships forged with the department and the school. Teachers may look the other way to avoid becoming involved in a situation in order to do no harm to themselves; thus, not only preserving their image within the school, but also their job. The ramifications can be great, especially when looking the other way may cause harm to a colleague, student, or the school. Shirley shared a story of when she became a principal at a socio-economically disadvantaged middle school. The status of the school provided for numerous grants to be awarded to cover the costs of technology improvements at the school and within the classrooms. None of the improvements nor items purchased per the grants were evident. Upon further investigation, the principal was able to pinpoint embezzlement by the technology teacher. What was startling, as Shirley described, "faculty at the school knew the technology teacher was pocketing funds by placing purchase orders for goods and upon receipt of the goods returning the items, asking the supplier to draft the refund check directly to the teacher." None of the staff who were aware of the situation reported the instances to administration. Other teachers who heard the rumors did not confront the technology teacher nor bring the situation to the attention of administration. When Shirley met with faculty, who knew of the situation, justification of replies included, "the technology teacher was not being paid enough by the district and he needed the money more than the students needed the technology in the classrooms." Some teachers also informed Shirley that they did not feel it was their responsibility to go to administration to report the situation. The laissez-faire and cavalier attitude of teachers at this particular school caused the principal, Shirley, to pause, questioning the culture of the school. An assistant principal, Hank, had noted there is a difference between self-preservation and job-preservation. Assistant principal Marsha stated, "teachers are more worried about self-preservation than job-preservation. The teacher's image and relationship with their peers are more important than doing the right thing to report an instance that constitutes unethical behavior." When the topic was discussed further, Marsha said that "teachers at the school are more concerned with the appearance of being benign, a non-trouble maker. They just want to come to school, do their job, and leave." Each of the participants shared similar observations and grew to understand that school culture, including building a relationship of trust among faculty, is needed in order to have a healthy school environment, one in which faculty and education leaders can work harmoniously when making sound ethical decisions that are in the best interest of the school community. 


\section{Discussion}

Based on the insights and knowledge acquired in observing faculty at their respective school sites, education leaders gained a deeper understanding of what is needed to improve ethical decision-making. Education leaders employ decision-making in the daily operations of the school or district based on personal and professional codes of ethics and those employed by the district for whom they work. The specific ethics as defined by the education leaders who participated in this study include due process, care, inclusion, professionalism, equality, and justice. The perceptions of the education leaders revealed a need to do a better job of faculty professional development, employ an awareness of the school community and authentic self, and seek innovative change to their leadership style to forge honest discussions and gain faculty trust.

The study revealed that education leaders have an empathic awareness of the ethical decision-making practices of their faculty. The education leaders in this study posited that for the most part faculty do make sound ethical decisions daily in support of the school community. In those instances when unethical behavior occurs at the school site, the education leaders believe they are not always immediately aware of the situation; instead, they may learn of it through other means.

The study confirmed the importance of education leaders developing relationships to promote trust and integrity among the faculty and school community (McCabe, 2013). For education leaders to incorporate an insightful and broader perspective, dig deeper, and think systemically, they must ask questions to improve school culture (Goldman \& Senge, 2014; Hollins, 2012). This awareness was based in part on traditional processes and practices of managing and observing faculty (Curry et al., 2016) at the school site and modeling ethical decision-making behaviors (Jordan et al., 2013; Lannon-Kim, 1991). Systems thinking and systemic change may contribute to developing an awareness of trust and mutual respect among education leaders and faculty (Cooper, 2004). To support this endeavor, education leaders need to shift focus on what is driving ethical decision-making, how teachers report issues of ethical concerns for possible investigation, and sitebased or district-level professional development training opportunities in the identification of ethical issues. Therefore, this study sought to unveil the systemic changes education leaders may implement based on breakthrough moments in the realization that they need to do more to promote a positive and ethical school culture.

To embody the tenets of authentic leadership, the individual leader's personal history, inclusive of life events, helps to inform and ultimately guides the development of the person and the leadership characteristics practiced (Gardner et al., 2005). An educational leader who employs authentic leadership must do so by practicing honesty and empathy, building trust, and generating enthusiastic support from those who work with them at the school site and within the school community. An education leader who is empathetic has the ability to understand others' perspectives and use this knowledge for the greater good of developing professional relationships among faculty (Yamamoto et al., 2014). When the education leader is reflexive in their learning, personal and professional growth occurs (Burnell \& Schnackenberg, 2014). Therefore, the education leader, as an authentic leader, is able to improve individual and team performance, which translates to a focus on people and the ethics of the organization (Gardner et al., 2011).

Within a school site and district, leaders should place a priority on creating an environment where all faculty are empowered to work collectively with education leaders to identify and collaboratively solve situations that may call for ethical decision-making in a manner that is in the best interest of all parties (Curry et al., 2016). Professional development training may include a focus on how faculty think carefully, critically, and effectively when faced with situations where they may need to enact ethical decision-making (Waller, 2011). Faculty within a school and district should feel comfortable, knowing that confidentiality will be upheld when expressing concerns regarding situations colleagues' conduct may be deemed. When faculty concerns are heard in a safe and trusting environment, teachers are more willing to identify the problem and play an important 
role in mitigating a solution in conjunction with education leaders (Massachusetts Department of Elementary and Secondary Education [MDESE], 2015). Professional development and training centered on ethical decision-making and situational awareness is a means to enact empowerment of faculty leading to enhanced efficacy (Martin et al., 2017; Yoo, 2016). Education leaders seeking to develop a school vision of learning are aware that a school culture supporting this vision is constructed of a set of "behavioral norms that exemplify the best that a school stands for. It means building an institution in which people believe strongly, with which they identify personally, and to which they gladly render their loyalty" (Razik \& Swanson, 2010, p. 123).

\section{Conclusions}

The process of ethical decision-making of faculty within public schools is a constant concern, largely based on news media stories, whether transmitted via television, radio, the internet, or social media, of educators who choose to conduct themselves unethically in a school environment. In many instances, the stories that are broadcasted publicly could have been resolved quickly if faculty at the school site or within a district would have reported the situation. The implication that education leaders would have knowledge that such behavior was taking place within a school is not easily discerned. This exploratory research encourages authentic education leadership development towards reflective practices and building a culture of trust, where ethical decision-making communication can commence freely with faculty. Faculty within a school and district should feel comfortable knowing that confidentiality will be upheld when they express concerns regarding situations in which the conduct of colleagues may be deemed unethical. When faculty concerns are heard in a safe and trusting environment, they are more willing to identify the problem and play an important role in mitigating a solution in conjunction with education leaders (MDESE, 2015). Education leaders may also benefit by developing an understanding of the role and relationship of faculty to the importance of making sound ethical decisions for the betterment of the school; thus, leading to a positive change in school culture.

The findings from this study may provide education leaders with a greater understanding of the constructs in which faculty make ethical decisions at their schools and the importance of including systems thinking to assess and develop programs to cultivate a positive culture of honesty and trust (Fiore \& Joseph, 2013). This study found that understanding school culture plays a formidable role in the relationships that are developed, maintained, and sustained between faculty and education leaders. When such relationships are developed within a school or district, with supportive practices, faculty may be more likely to routinely practice ethical decision-making when faced with ethical dilemmas, knowing the education leadership will be supportive. The results of this study may add to the body of knowledge of school reform, ethical decision-making processes, systems thinking, and purposeful change. 


\section{References}

Avolio, B. J., Walumbwa, F. O., \& Weber, T. J. (2009). Leadership: Current events theories, research, and future directions. Annual Review of Psychology, 6o, 421-449.

Blumberg, A. (1989). School administration as a craft: Foundations of practice. Allyn \& Bacon.

Boon, H. J. (2011). Raising the bar: Ethics education for quality teachers. Australian Journal of Teacher Education, 36(7), 104-121. https://doi.org/10.14221/ajte.2011v36n7

Burnell, B., \& Schnackenberg, H. (Eds.). (2014). The ethics of cultural competence in higher education. Taylor \& Francis.

Campbell, E. (2003). The ethical teacher. Open University Press.

Campbell, E. (2008). The ethics of teaching as a moral profession. Curriculum Inquiry, 38(4), 357-385.

Carmel-Gilfilen, C., \& Portillo, M. (2016). Designing With Empathy: Humanizing Narratives for Inspired Healthcare Experiences. HERD: Health Environments Research \& Design Journal, 9(2), 130-146. https://doi.org/10.1177/1937586715592633

Charles, J., Cheung, R., \& Rosekrans, K. (2016, November 17-21). The case of assessment center: How the purpose, logic and experience of an embedded performance assessment of school leaders is built around an epistemology of practice [Paper presentation]. University Council for Education Administration Conference. Detroit, MI.

Cooper, D. E. (2004). Ethics for professionals in a multicultural world. Pearson.

Curry, J. R., Webb, A. W., \& Latham, S. J. (2016). A content analysis of images of novice teacher induction: First-semester themes. Journal of Educational Research and Practice, 6(1), 43-65. https://doi.org/10.5590/JERAP.2016.06.1.04

Dawson, K., \& Kelin, D. A. (2014). The reflexive teaching artist: Collected wisdom from the drama/theatre field. Intellect, Ltd.

Demir, S., \& Karakus, M. (2015). The relationship between ethical climate and trust and motivation levels of teachers and students. Educational Administration: Theory and Practice. 21(2), 183-212.

Dolgoff, R., Harrington, D., \& Loewenberg, F. M. (2011). Ethical decisions for social work practice (ethics \& legal issues) (9th ed.). Brooks/Cole.

Englander, M. (2012). The interview: Data collection in descriptive phenomenological research. Journal of Phenomenological Psychology, 43, 13-35. https://doi.org/10.1163/156916212X632943

Erie, D. J. (2013). The role of general education in the development of ethical reasoning in college students: A qualitative study on the faculty perspective [Unpublished doctoral dissertation]. University of Nebraska-Lincoln. http://digitalcommons.unl.edu/cehsedaddiss/154

Feldman, A., Altrichter, H., Posch, P., \& Somekh, B. (2018). Teachers investigate their work: An introduction to action research across the professions (3rd ed.). Routledge.

Finfgeld-Connett, D. (2013). Use of content analysis to conduct knowledge-building and theory-generating qualitative systematic reviews. Qualitative Research, 14(3), 341-352. https://doi.org/10.1177/1468794113481790

Fiore, D., \& Joseph, C. (2013). Making the right decisions: A guide for school leaders. Taylor \& Francis.

Gardner, W. L., Avolio, B. J., Luthans, F., May, D. R., \& Walumbwa, F. O. (2005). “Can you see the real me?” A self-based model of authentic leader and follower development. Leadership Quarterly, 16, 343372. https://doi.org/10.1016/j.leaqua.2005.03.003 
Gardner, W. L., Cogliser, C. C., Davis, K. M., \& Dickens, M. P. (2011). Authentic leadership: A review of the literature and research agenda. Leadership Quarterly, 22, 1120-1145.

https://doi.org/10.1016/j.leaqua.2011.09.007

Goldman, D., \& Senge, P. (2014). The triple focus: A new approach to education. More than Sound.

Hannah, S. T., Avolio, B. J., Luthans, F., \& Harms, P. (2008). Leadership efficacy: Review and future directions. The Leadership Quarterly, 19, 669-692. https://doi.org/10.1016/j.leaqua.2008.09.007

Hartman, R. J., Johnston, E., \& Hall, M. (2017). Empathetic design: A sustainable approach to school change. Discourse and Communication for Sustainable Education, 8(2), 38-56. https://doi.org/10.1515/dcse-2017-0014

Hollins, E. (2012). Learning styles. In J. A. Banks (Ed.) Encyclopaedia of Diversity. SAGE Publications, Inc.

Johnston, E., Rasmusson, X., Foyil, B., \& Shopland, P. (2017). Witnesses to transformation: Family member experiences providing individualized music to their relatives with dementia. Cogent Education, 4(1), 1362888. https://doi.org/10.1080/2331186X.2017.1362888

Jones, I. C., \& Blake, V. J. (2018). Fearless conversations school leaders have to have (1st ed.). Corwin.

Jordan, J., Brown, M., Trevino, L., \& Finkelstein, S. (2013). Someone to look up to: Executive followerexecutive reasoning and perceptions of ethical leadership. Journal of Management, 39 (3), 66-683. https://doi.org/10.1177/0149206311398136

Kolko, J. (2010). Abductive thinking and sensemaking: The drivers of design synthesis. Design Issues, 26(1), 15-28. https://doi.org/10.1162/desi.2010.26.1.15

Kuusisto, E., Tirri, K., \& Rissanen, I. (2012). Finnish teachers' ethical sensitivity. Education Research International, 2012, 1-10. https://doi.org/10.1155/2012/351879

Lannon-Kim, C. (1991). Revitalizing the schools: A systems thinking approach. The Systems Thinker, 2(5), 1-5.

Marshall, C., \& Rossman, G. (2016). Designing qualitative research (6th ed). SAGE Publications, Inc.

Martin, L. E., Kragler, S., \& Frazier, D. (2017). Professional development and educational policy: A comparison of two fields in education. Journal of Educational Research and Practice, 7(1), 60-73. https://doi.org/10.5590/JERAP.2017.07.1.05

Marzano, R. J., Waters, T., \& McNulty, B. A. (2005). School leadership that works: From research to results. Association for Supervision and Curriculum Development.

Massachusetts Department of Elementary and Secondary Education (MDESE). (2015). Building a school culture that supports teacher leadership.

McCabe, C. (2013). The fearless school leader: Making the right decisions. Taylor \& Francis.

Merriam, S. B. (2009). Qualitative research: A guide to design and implementation. Jossey-Bass.

Palinkas, L., Horwitz, S., Green, C., Wisdom, J., Duan, N., \& Hoagwood, K. (2015). Purposeful sampling for qualitative data collection and analysis in mixed method implementation research. Administration \& Policy in Mental Health \& Mental Health Services Research, 42(5), 533-544. https://doi.org/10.1007/s10488-013-0528-y

Patton, M. Q. (2002). Qualitative research and evaluation methods (3rd ed.). Sage.

Razik, T., \& Swanson, A. (2010). Fundamental concepts of educational leadership and management. Allyn \& Bacon.

Saldana, J. (2015). The coding manual for qualitative researchers (3rd ed.). SAGE Publications, Inc. 
Saunders, B., Sim, J., Kingstone, T., Baker, S., Waterfield, J., Bartlam, B., Burroughs, H., \& Jinks, C. (2018). Saturation in qualitative research: Exploring its conceptualization and operationalization. Quality and Quantity, 52, 1893-1907. https://doi.org/10.1007/s11135-017-0574-8

Schulte, L. E., Thompson, F., Talbott, J., Luther, A., Garcia, M., Blanchard, S., Conway, L., \& Mueller, M. (2002). The development and validation of the ethical climate index for middle and high schools. The School Community Journal, 12(2), 117-132.

Shapiro, J., \& Stefkovich, J. (2011). Ethical leadership and decision making in education (3rd Ed). Routledge.

van Nuland, S. (2009). Teacher codes: Learning from experience. UNESCO/International Institute for Educational Planning.

Waller, B. N. (2011). Consider ethics: Theory, reading, and contemporary issues (3rd ed.). Prentice Hall.

White, M. D., \& Marsh, E. E. (2006). Content analysis: A flexible methodology. Library Trends, 55(1), 22-45. https://doi.org/10.1353/lib.2006.0053

Yamamoto, J. K., Gardiner, M. E., \& Tenuto, P. L. (2014). Emotion in leadership: Secondary school administrators' perceptions of critical incidents. Educational Management Administration and Leadership, 42(2), 165-183. https://doi.org/10.1177/1741143213499260.

Yin, R. K. (2013). Case study research: Design and methods (5th ed.). SAGE.

Yoo, J. H. (2016). The effect of professional development on teacher efficacy and teachers' self-analysis of their efficacy change. Journal of Teacher Education for Sustainability, 18(1), 84-94. https://doi.org/10.1515/ites-2016-0007

Young, M., \& Mawhinney, H. (2012). The research base supporting the ELCC standards. University Council for Educational Administration. http://www.ucea.org/resource/the-research-base-supporting-theelcc-standards/

Ziegler, M., Paulus, T., \& Woodside, M. (2006). Creating a climate of engagement in a blended learning environment. Journal of Interactive Learning Research, 17(3), 295-318. https://www.learntechlib.org/primary/p/6286/ 
Burleigh, 2020

\section{Appendix 1}

\section{Interview Questions, Semi-Structured}

1. How do you define ethics?

2. How do you define ethics in the context of the school site or district?

3. Does the school and/or district have policies in place regarding ethics and ethical behavior?

4. Based on your observations, how does your faculty define ethics?

5. Does the school's faculty know when an ethical decision is being made? Please provide an example.

6. What types of unethical decision-making instances have you observed as an education leader?

7. What is an example of faculty who have made decisions that are unethical?

8. What was the outcome of the example provided?

9. How does faculty react when observing a colleague who is not being ethical in their decision-making? Can you share an example?

10. What are some factors that may cause a faculty member to not report an observed instance of a colleague being unethical in the classroom or at the school site to the school site administrator(s)?

11. How does non-action affect the relationship between faculty and the school's leadership?

12. If a faculty member would not report an observed instance to school site administration, who may they report the instance to?

13. Would a standard or universal educational code of ethics change faculty perceptions of reporting instances in the classroom or with fellow staff members to the school's leadership or administration? Why or why not?

14. How would a standard code of ethics affect the relationship between faculty and the school's administration?

15. What type of training is available to education leaders and administrators in educational ethics and leadership?

16. What type of professional development is needed to change faculty perception of administration or the school's/district's leadership to feel confident and comfortable in reporting an observed instance of unethical behavior by a faculty member?

17. What other systemic change(s) may be needed to improve the relationship between faculty and education leaders at the school site or within the district?

18. Would these systemic changes lead to positive change at the school site or within the district?

19. How can changes in an educator's leadership style affect the school site and community, when effectively and honestly employed, to help redefine a school's and district's culture?

20. What are your suggestions to address concerns of ethical decision-making issues among faculty?

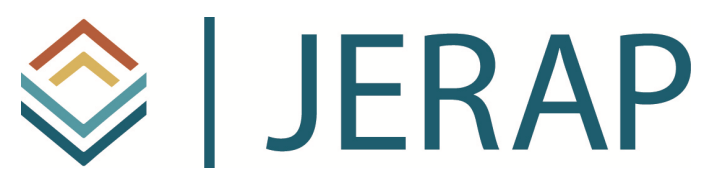

The Journal of Educational Research and Practice is a peerreviewed journal that provides a forum for studies and dialogue about developments and change in the field of education and learning. The journal includes research and related content that examine current relevant educational issues and processes. The aim is to provide readers with knowledge and with strategies to use that knowledge in educational or learning environments. JERAP focuses on education at all levels and in any setting, and includes peer-reviewed research reports, commentaries, book reviews, interviews of prominent individuals, and reports about educational practice. The journal is sponsored by the Richard W. Riley College of Education and Leadership at Walden University, and publication in JERAP is always free to authors and readers. 